\title{
EXPERIMENTAL STUDY ON THE HOLE QUALITY DURING ABRASIVE WATERJET DRILLING OF CFRP
}

\section{Panagiotis Karmiris-Obratański ${ }^{1,2}$, Nikolaos E Karkalos ${ }^{1}$, Dimitrios Skondras-Giousios ${ }^{1}$, Emmanouil-Lazaros Papazoglou ${ }^{1}$, Panagiotis Kyratsis ${ }^{3}$, Angelos P Markopoulos ${ }^{1}$}

\author{
${ }^{1}$ School of Mechanical Engineering, Laboratory of Manufacturing Technology, National Technical University of Athens, \\ Heroon Polytechniou 9, 15780, Athens, Greece \\ ${ }^{2}$ Faculty of Mechanical Engineering and Robotics - Department of Manufacturing Systems, \\ AGH University of Science and Technology, Avenue A. Mickiewicza 30, 30-059 Cracow, Poland \\ ${ }^{3}$ University of Western Macedonia, Kila Kozani GR50100, Greece
}

Corresponding author: Angelos Markopoulos, amark@mail.ntua.gr

\begin{abstract}
Abrasive Waterjet (AWJ) machining is considered an excellent alternative to conventional machining processes due to its superb machining characteristics. More specifically, Abrasive Waterjet drilling is nowadays a promising nonconventional process for obtaining high quality holes. In the present study, drilling experiments based on Taguchi L9 orthogonal design method were conducted via AWJ on carbon fiber reinforced polymer (CFRP) plate at various waterjet parameters, namely, different pressure, abrasive mass flow rate and standoff distance values. The purpose of the experiments was to investigate the impact of these process parameters on the quality of holes. The hole quality was determined by measuring the hole diameter error as well as the hole taper. The optical evaluation was implemented with the use of optical microscope and special measuring software. The ANOVA analysis of the results showed a significant influence of standoff distance regarding the hole diameter error and a combined influence of waterjet pressure and standoff distance regarding the hole taper. Furthermore, the optimal process parameter values for the optimization of the hole diameter error and hole taper were determined. The hole quality in terms of defects appearance was also quantitatively inspected, through optical imaging.
\end{abstract}

Key words: Abrasive waterjet drilling. Hole quality. Waterjet pressure. Standoff distance. CFRP

\section{INTRODUCTION}

Drilling is one of the most established machining processes, which finds extensive use in numerous modern industries, especially automotive and aerospace ones, as it is essential during the fabrication of various mechanical parts. The strict requirements of high dimensional accuracy and quality as well as highest possible productivity can be met both with conventional and non-conventional methods. Conventional drilling leads to relatively high mechanical and thermal stress and rapid tool wear results in an increase of cost especially in the case of hard-to-cut materials. On the other hand, nonconventional techniques can lead to higher accuracy and productivity during drilling.

More specifically, one of the most promising alternative non-conventional processes is Abrasive Waterjet (AWJ) machining, which involves minimal cutting heat and waste whereas it can render a variety of features of different sizes and is able to process all material categories including metals, ceramics and composites (Natajaran et al., 2020). Regarding composites, drilling poses additional challenges due to the increased possibility of defects occurrence such as fiber delamination, burr and pull-out. In order to achieve the better possible quality and efficiency during drilling, appropriate choice of process parameters is required. In the relevant literature various studies regarding AWJ drilling of composites are conducted with this goal. For example, (Prasad and Chaitanya, 2018) studied the effect of process parameters such as abrasive mass flow rate, waterjet pressure, standoff distance as well as fiber orientation on the material removal rate (MRR), surface roughness (Ra) and hole accuracy. MRR was mainly affected by abrasive mass flow rate, Ra was mainly affected by standoff distance and hole accuracy by both pressure and standoff distance, whereas overall standoff distance was proven to be the most important parameter. In a later study, Siva Prasad and Chaitanya (Prasad and Chaitanya, 2021) included more parameters such as the abrasive mesh size and workpiece thickness and noted that higher pressure and abrasive mass flow rate lead to better surface roughness whereas lower standoff distance improves cutting performance.

Alberdi et al. (Alberdi et al, 2016) investigated the impact of process parameters on the surface roughness and taper angle during drilling of Ti6Al4V/CFRP stacks. The results indicated that 
waterjet pressure and traverse speed affected more the taper angle which decreased at higher pressure values and that surface roughness increased considerably for increasing traverse speed values. Thongkaew et al. (Thongkaew et al., 2016) conducted AWJ drilling experiments on carbon fiber PEEK reinforced sheets in order to determine the dimensional accuracy of the produced holes under various process conditions. In this study, holes of different diameters were produced under different water pressure, traverse speed and abrasive mass flow rate values. It was found that hole diameter error decreases at lower pressure and higher traverse speed values whereas hole roundness and inclination angle were more affected by traverse speed.

Phapale et al. (Phapale et al., 2016) studied the impact of process parameters on the delamination and exit hole diameter using also various alternative drilling strategies. Kakinama et al. (Kakinama et al., 2015) compared a novel technique of highspeed conventional drilling and non-conventional methods such as ultrasonic and AWJ drilling for drilling of composites and concluded that the proposed technique was possible to achieve higher quality of holes and process efficiency. Montesamo et al. (Montesamo et al., 2017) also compared conventional and AWJ drilling methods not only regarding hole quality but also regarding mechanical properties of the machined hole. They noted that although AWJ drilling showed inferior results in terms of surface roughness it provided holes with superior long-term fatigue performance at high stresses whereas at static conditions and regarding short-term fatigue performances both methods were equivalent.

In the present study AWJ drilling experiments were conducted on a carbon fiber reinforced polymer (CFRP) workpiece under various waterjet pressure, abrasive mass flow rate and standoff distance values in a relatively wide range in order to be able to observe their effect on hole diameter error and hole taper. The results were analyzed using statistical methods in order to determine the correlation between process parameters and its outcome. Finally, the optimum parameter values for the reduction of hole diameter error and taper are determined.

\section{METHODOLOGY}

In the current study, experiments concerning AWJ drilling of CFRP were carried out based on Taguchi L9 orthogonal array for three control parameters, namely, waterjet pressure $(\mathrm{P})$, standoff distance $(\mathrm{h})$ and abrasive mass flow rate (ma), at three levels each. Waterjet pressure was varied in a relatively wide range, namely between 100 and $400 \mathrm{MPa}$, standoff distance was varied between 1 and $6 \mathrm{~mm}$ and abrasive mass flow rate between 2 and $8 \mathrm{~g} / \mathrm{s}$, as can be seen in Table 1. For the experiments a H.G. RIDDER-Automatisierungs GmbH model HWE1520 AWJ machine was utilized. In all the experiments, the abrasive material was garnet of nominal mesh size 80 , while, the diameter of the focusing tube was $1 \mathrm{~mm}$ and the waterjet nozzle diameter $0.3 \mathrm{~mm}$. Holes with nine combinations of the process parameters of Table 1 were made along an orthogonal CFRP plate with a thickness of $5 \mathrm{~mm}$.

Table 1. Process parameters and their levels

\begin{tabular}{|c|c|c|c|}
\hline \multirow{2}{*}{ Parameter } & \multicolumn{3}{|c|}{ Levels } \\
\cline { 2 - 4 } & 1 & 2 & 3 \\
\hline $\begin{array}{c}\text { Waterjet Pressure } \\
(\mathrm{MPa})\end{array}$ & 100 & 250 & 400 \\
\hline $\begin{array}{c}\text { Standoff distance } \\
(\mathrm{mm})\end{array}$ & 1 & 3.5 & 6 \\
\hline $\begin{array}{c}\text { Abrasive mass } \\
\text { flow rate (g/s) }\end{array}$ & 2 & 5 & 8 \\
\hline
\end{tabular}

After the experiments were conducted, the diameter of the produced holes, both on the entry and exit side was measured using high resolution images obtained by an optical microscope and special measuring software. Subsequently, the error of the hole diameter and the hole taper, which is determined as the ratio of hole diameter in the entry and exit sides, were calculated. The aforementioned measurements were taken by utilizing a VHX-7000 ultra-deep-field microscope (KEYENCE, Mechelen, Belgium), equipped with an x20-2000 objective lens. The measuring technique was based on the Focus Variation Microscopy (FVM), which is mainly similar to confocal microscopy. More specifically, in FVM a white light beam coming from a LED source passes through a semi-transparent mirror and a lens before it reaches the measuring surface. The reflected light from the focused areas returns through the lens, while, a beam splitter directs it onto a photonic detector that records the respective geometric and photometric information. Thus, by employing the FVM, colorful high-resolution 3D surface measurements can be obtained, by combining the small depth of a classical optical system with vertical scanning.

\section{RESULTS AND DISCUSSION}

Before the results' presentation and analysis, it is worth observing some characteristic images of the entry and exit side of holes produced by AWJ drilling process. In Figure 1, images of holes under three different conditions are presented. At first, it can be seen that the quality of the exit side of the holes is slightly better as the jet had lower energy when it reached the outer side of the hole whereas the damage is obviously higher in the entry side and more defects such as fiber pull-out can be observed. 


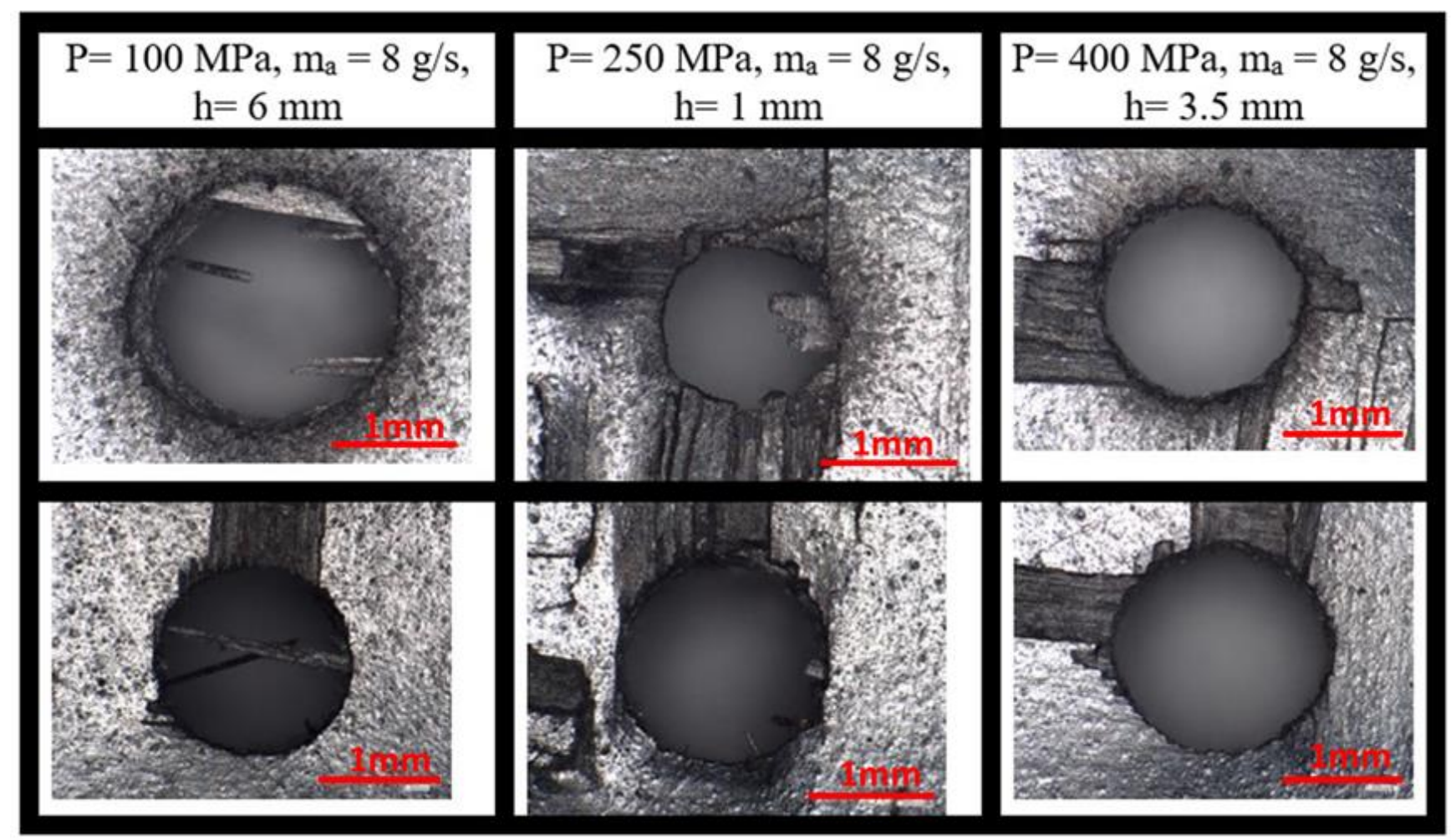

Fig.1. Images of holes obtained by AWJ drilling under various conditions; in the upper row the entry side is depicted whereas in the lower row the exit side of the respective hole is depicted

Table 2. Experimental results

\begin{tabular}{|c|c|c|c|c|c|c|c|}
\hline No. & $\mathrm{P}(\mathrm{MPa})$ & $\mathrm{m}_{\mathrm{a}}(\mathrm{g} / \mathrm{s})$ & $\mathrm{h}(\mathrm{mm})$ & $\begin{array}{c}\text { Entry } \\
\text { hole } \\
\text { diameter } \\
(\mathrm{mm})\end{array}$ & $\begin{array}{c}\text { Exit } \\
\text { hole } \\
\text { diameter } \\
(\mathrm{mm})\end{array}$ & $\begin{array}{c}\text { Hole } \\
\text { diameter } \\
\text { error } \\
(\mathrm{mm})\end{array}$ & $\begin{array}{c}\text { Hole } \\
\text { taper }\end{array}$ \\
\hline 1 & 100 & 2 & 1 & 1.730 & 1.445 & 0.730 & 1.196 \\
\hline 2 & 100 & 5 & 3.5 & 1.795 & 1.820 & 0.795 & 0.986 \\
\hline 3 & 100 & 8 & 6 & 2.207 & 1.667 & 1.207 & 1.324 \\
\hline 4 & 250 & 2 & 3.5 & 2.062 & 1.624 & 1.062 & 1.270 \\
\hline 5 & 250 & 5 & 6 & 2.155 & 1.934 & 1.155 & 1.115 \\
\hline 6 & 250 & 8 & 1 & 1.241 & 1.760 & 0.241 & 0.705 \\
\hline 7 & 400 & 2 & 6 & 1.889 & 1.782 & 0.899 & 1.060 \\
\hline 8 & 400 & 5 & 1 & 1.265 & 1.656 & 0.265 & 0.764 \\
\hline 9 & 400 & 8 & 3.5 & 1.711 & 1.861 & 0.711 & 0.919 \\
\hline
\end{tabular}

The results regarding the hole diameter error and hole taper in each experiment are presented in Table 2.

The hole diameter error was calculated as the difference between the measured entry hole diameter and the nominal diameter of $1 \mathrm{~mm}$, which is the diameter of the focusing tube. In Figure 2, the effect of each process parameter hole diameter error is displayed. It can be seen that increase of waterjet pressure and mass flow rate as well as decrease of standoff distance lead to lower hole diameter error. Increase of pressure and mass flow rate lead to higher jet energy and better cut whereas lower standoff distance leads to smaller affect area and thus hole diameter closer to the nominal one. Moreover, it can be seen that standoff distance variation leads to a larger variation of hole diameter error than the variation produced by increasing the two other parameters. The ANOVA results confirm these observations and reveal that the relative significance of the three parameters is $12.5 \%, 4.82 \%$ and $69.76 \%$ for waterjet pressure, abrasive mass flow rate and standoff distance respectively. The optimum parameter values for minimization of the hole diameter error are: 250 MPa waterjet pressure, $8 \mathrm{~g} / \mathrm{s}$ abrasive mass flow rate and $1 \mathrm{~mm}$ standoff distance. Furthermore, the results regarding hole taper were analyzed as it is also an 
important quantity for the assessment of hole quality. As can be seen in Figure 3, the taper decreases with an increase of the waterjet pressure and abrasive mass flow rate, up to a point. Moreover, it decreases considerably with lower standoff distance.

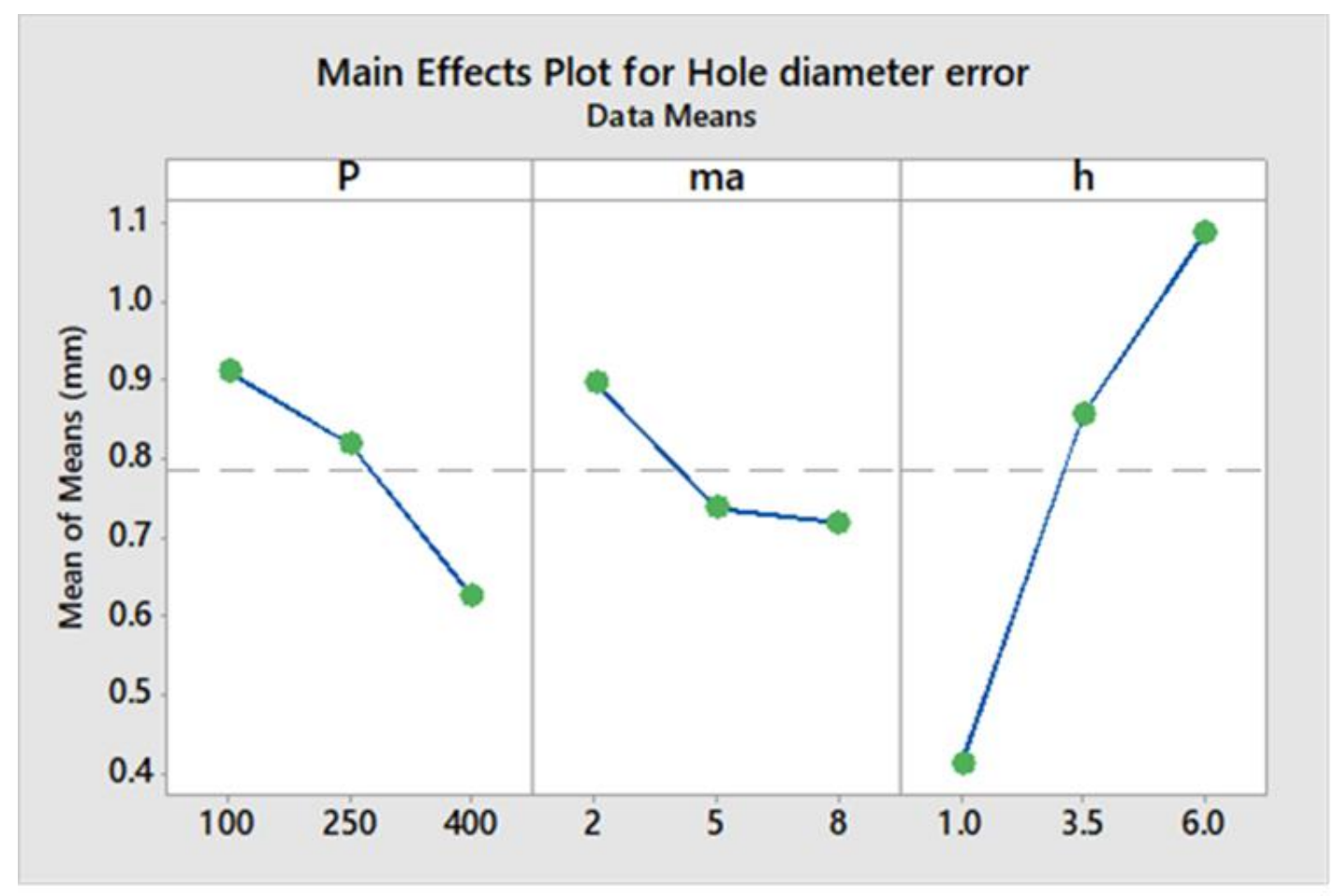

Analysis of Variance

\begin{tabular}{|c|c|c|c|c|}
\hline Source & DF Seq SS & Adj SS Adj MS & -Value & D-Value \\
\hline Regression & 30.85302 & $87.07 \% 0.853020 .28434$ & 11.23 & 0.012 \\
\hline $\mathrm{P}$ & 10.12241 & $12.50 \% 0.122410 .12241$ & 4.83 & 0.079 \\
\hline $\mathrm{ma}$ & 10.04717 & $4.82 \% 0.047170 .04717$ & 1.86 & 0.231 \\
\hline $\mathrm{h}$ & 10.68344 & $69.76 \% 0.683440 .68344$ & 26.99 & 0.003 \\
\hline Error & 50.12663 & $12.93 \% 0.126630 .02533$ & & \\
\hline Total & 80.97965 & $100.00 \%$ & & \\
\hline
\end{tabular}

Fig.2. Main effects plot for the hole diameter error and ANOVA results

The ANOVA results show that the relative importance of each of the process parameters is $26.24 \%, 15.06 \%$ and $31.35 \%$ for waterjet pressure, abrasive mass flow rate and standoff distance respectively. The optimum parameters values for obtaining a taper value of 1.0, which ideally indicates a hole with equal diameter at its entry and exit sides are: $100 \mathrm{MPa}$ waterjet pressure, $5 \mathrm{~g} / \mathrm{s}$ abrasive mass flow rate and $3.5 \mathrm{~mm}$ standoff distance. Finally, it is noteworthy that for certain machining parameters combination, reverse taper is occurred, namely, the exit hole diameter is greater that the entry hole's. In literature, it is established that reverse taper (negative taper angle) occurs mainly due to the cutting speed, when its value is lower than the critical one that is required in order to ensure a smooth cut surface with almost zero tapering, under specific machining parameters. As a rule of thumb, it can be said that higher from the optimal cutting speeds leads in typical V-shaped taper, lower cut speeds in reverse taper, while, in cases of very thick workpieces, barrel like taper may occur (Krajcarz et al., 2017). 


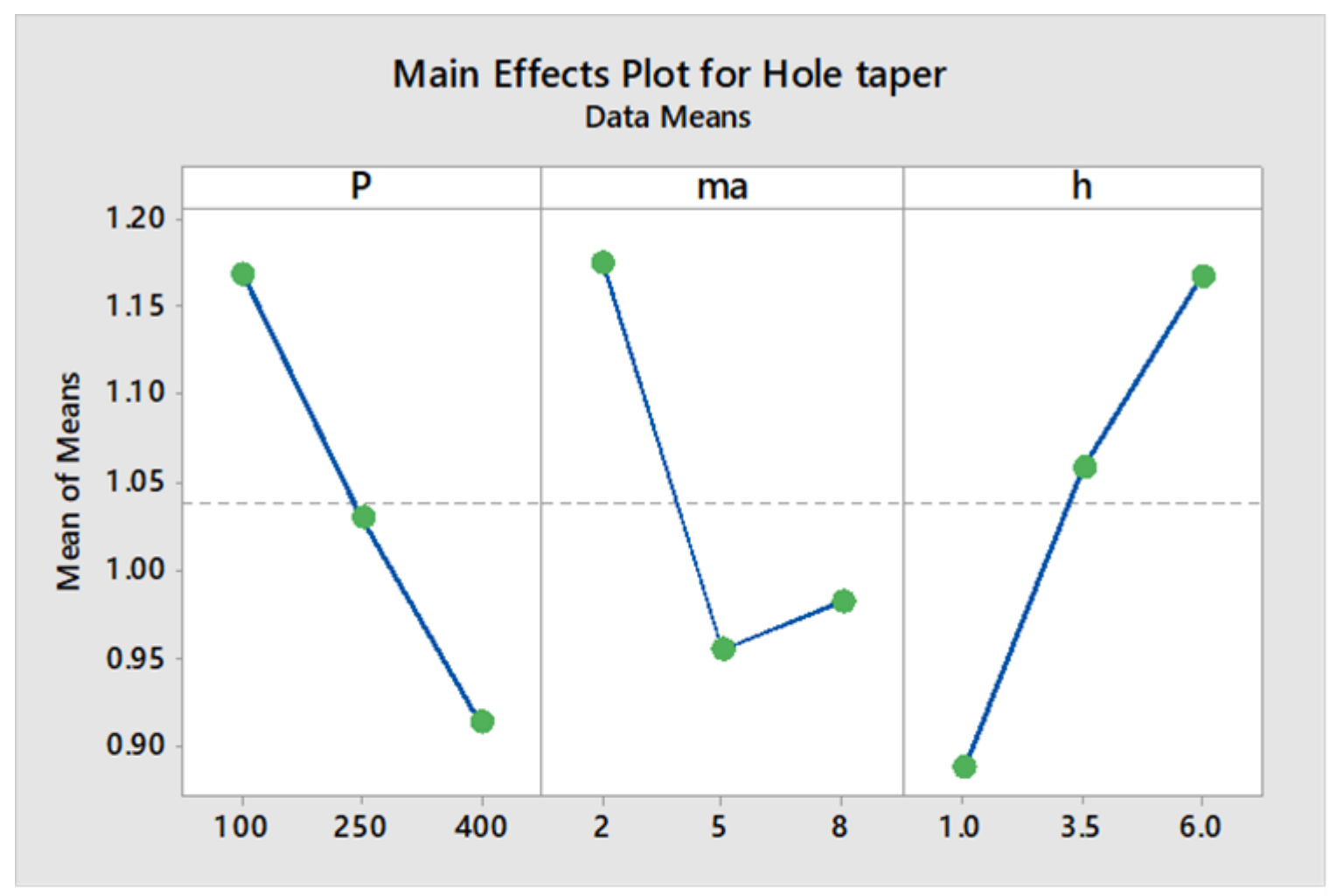

\section{Analysis of Variance}

Source DF Seq SS Contribution Adj SS Adj MS F-Value P-Value

\begin{tabular}{|c|c|c|c|c|}
\hline Regression & 30.26863 & $72.64 \% 0.268630 .08954$ & 4.42 & 0.072 \\
\hline $\mathrm{P}$ & 10.09703 & $26.24 \% 0.097030 .09703$ & 4.79 & 0.080 \\
\hline $\mathrm{ma}$ & 10.05568 & $15.06 \% 0.055680 .05568$ & 2.75 & 0.158 \\
\hline $\mathrm{h}$ & 10.11593 & $31.35 \% 0.115930 .11593$ & 5.73 & 0.062 \\
\hline Error & 50.10119 & $27.36 \% 0.101190 .02024$ & & \\
\hline Total & 80.36983 & $100.00 \%$ & & \\
\hline
\end{tabular}

Fig. 3. Main effects plot for the hole taper and ANOVA results

\section{CONCLUSIONS}

In this study, a CFRP workpiece underwent AWJ drilling experiments in order to determine how relatively wide range changes in machining parameters such as abrasive mass flow rate, waterjet pressure, and standoff distance affect the hole quality. Quality assessment of the drilled holes was made by measuring diameter error as well as the hole taper, using an optical microscope and measuring software. The correlation between the process parameters and the obtained results was analyzed via ANOVA. The following conclusions were deducted from the analysis of the experimental results:

- Regarding the hole diameter error, the process parameter with the most significant influence was found to be the standoff distance, with a relative importance of $69.76 \%$.

- The experimental results on determining the most influential process factors for the hole taper showed that waterjet pressure and standoff distance were most important, with a relative significance of $26.24 \%$ and $31.35 \%$, respectively.

- For minimizing the hole diameter error, the optimum machining parameters are $250 \mathrm{MPa}$ waterjet pressure, $8 \mathrm{~g} / \mathrm{s}$ abrasive flow mass and $1 \mathrm{~mm}$ standoff distance.

- The optimum process parameter values for the obtaining a taper value of 1.0 are

- $100 \mathrm{MPa}$ waterjet pressure, $5 \mathrm{~g} / \mathrm{s}$ abrasive flow mass and $3.5 \mathrm{~mm}$ standoff distance. 


\section{REFERENCES}

1. Natajaran Y, Murugesan PK, Mohan M, Khan SALA (2020) Abrasive Water Jet Machining process: A state of art of review. Journal of Manufacturing Processes, 49, 271-322.

2. Siva Prasad K, Chaitanya DG (2018) Selection of optimal process parameters by Taguchi method for drilling GFRP composites using abrasive water jet machining technique. Materials Today: Proceedings 5, 19714-19722.

3. Siva Prasad K, Chaitanya G (2021) Optimization of process parameters on surface roughness during drilling of GFRP composites using taguchi technique. Materials Today: Proceedings 39(4): 1553-1558.

4. Alberdi A, Artaza T, Suarez A, Rivero A, Girot F (2016) An experimental study on abrasive waterjet cutting of CFRP/Ti6Al4V stacks for drilling operations. The International Journal of Advanced Manufacturing Technology 86, 691-704.

5. Thongkaew K, Wang J, Yeoh GH (2016) An investigation of hole machining process on a carbonfiber reinforced plastic sheet by abrasive waterjet. Advanced Materials Research 1136: 113-118.

6. Phapale K, Singh R, Patil S, Singh RKP (2016) Delamination characterization and comparative assessment of delamination control techniques in abrasive water jet drilling of CFRP. Procedia Manufacturing 5, 521-535.

7. Kakinuma $\mathrm{Y}$, Ishida $\mathrm{T}$, Koike $\mathrm{R}$, Klemme $\mathrm{H}$, Denkena B, Aoyama T (2015) Ultrafast feed drilling of carbon fiber-reinforced thermoplastics. Procedia CIRP 35, 91-95.

8. Montesano J, Bougherara H, Fawaz Z (2017) Influence of drilling and abrasive water jet induced damage on the performance of carbon fabriclepoxy plates with holes. Composite Structures 163: 257266.

9. Krajcarz D., Bańkowski D., Młynarczyk P. (2017) The Effect of Traverse Speed on Kerf Width in AWJ Cutting of Ceramic Tiles. Procedia Engineering 192: 469-473
Received: August 23, 2021 / Accepted: December 15, 2021 / Paper available online: December 20, 2021 () International Journal of Modern Manufacturing Technologies. 